\title{
Interdependency of Value for Money and Ex-Post Performance Indicators of Public Private Partnership Projects
}

\author{
Khalid Almarri ${ }^{1}$ and Halim Boussabaine ${ }^{2}$ \\ ${ }^{1}$ Assistant Professor, Faculty of Engineering and IT, the British University in Dubai, P.O. Box 345015, Dubai \\ International Academic City, Dubai, United, E-mail: khalid.almarri@buid.ac.ae (corresponding author). \\ ${ }^{2}$ Professor of Project Management, Faculty of Engineering and IT, the British University in Dubai, P.O. Box 345015, \\ Dubai International Academic City, Dubai, United, E-mail: halim@buid.ac.ae
}

Project Management
Received March 16, 2017; received revisions April 28, 2017; June 8, 2017; accepted June 15, 2017

Available online June 28, 2017

\begin{abstract}
One of the most important reasons for selecting public private partnerships (PPP) as a procurement method for infrastructure projects, is the ability to deliver the best value for money (VFM) under certain conditions. Several studies have identified and analysed the factors that contribute the value for money creation, and others have identified the most viable project success evaluation criteria. This paper aims to empirically examine the relationship between the PPP project ex-post performance and the value for money creation factors. 92 PPP experts from the UK and the UAE participated in this research via an online questionnaire. The questionnaire consisted of VFM factors, PPP performance indicators and several demographic questions. It was found, through the Pearson Correlation Coefficient and Regression analyses, that there was a significant and positive relationship between improved facilities factor to the users and time, quality, economic benefits and scope variation performance of PPP projects. The results of the analysis also showed clear output specification and early service delivery factors contribute only to the performance in terms of service and cost. Interestingly, the results of the analysis showed that optimisation of assets efficiency factor contributed negatively to the scope of variation of projects. The research also, through the regression analysis, showed that sector, experience and job position have no mediating role between PPP ex-post performance and VFM factors. This study confirmed the need for strict criteria in order to describe the achievement of success in PPP projects. These criteria ensure that the actual practice can be measured against the criteria which are set at the start of the project. This paper expanded empirically on the current literature on the relationship between the VFM and PPP project performance (specifically the ex-post performance).
\end{abstract}

Keywords: Public procurement, PPP, critical success factors, value for money, ex-post performance.

\section{Introduction}

The concept of public private partnership (PPP) came to the UK in 1997. The concept was already present in the country, but was classified within the sector of private finance initiative (PFI) that was introduced in the country in 1992 by the government of that time (Broadbent and Laughlin, 2003, 2004). PPP ventures have the ability to maximize the potential of developing public projects. According to a few sources, the presence of the private sector in the norm of public services adds more value to these services (Almarri and Abu Hijleh, 2017; Broadbent and Laughlin, 2004; Williams, 2016).

The private sector is more capable of improving outputs, reducing business risk and using technological advancements to reduce the life cycle costs of certain types of projects (P3, 2011; EPEC, 2012). The integration of project development stages is better produced through the efforts of PPPs. The different elements that are integrated include the planning, managing and funding of projects. Other elements include the actual construction and maintenance of the tangible project and all of these elements are provided by private investors (Almarri and Blackwell, 2014; Broadbent and Laughlin, 2003; EU, 2003). PPP projects always intend to use the experience and expertise of the private sector in order to best manage public services and provide the benefits of innovation, efficiency and improved quality with better financing (Osei-Kyei and Chan, 2015).

One of the important reasons for selecting PPP is that such projects simply return the best value for money under certain conditions. The value for money delivered in a PPP depends on correctly identifying risks in a project and then allocating them to parties who are most capable of lowering them to manage the project in the best manner. The principle here is to ensure that each risk is allocated to the party who has shown a proven ability to control the 
risk and decrease its impact on a project. The party should also be capable of easily facing the consequences of risky propositions by incurring the lowest financial impact (Almarri and Abu Hijleh, 2017; Chou et al., 2012; WBI, 2012).

PPP method has seen a lot of progress in the recent years, because people and organisations believe that it offers greater value for money (VFM). However, a recent report that evaluates the PPP projects carried out by the UK government, finds that most projects are expensive and do not deliver on their promise of providing the best value for money (The National Council for PPP, 2012). The main challenge for the current PPP industry is to ensure that all projects can be financed in a way that they are able to deliver good VFM performance. There is an argument among some authors that this failure in PPPs is attributed to the shortage of effective methods for measuring PPP project performance. Studies indicate that there are various value for money factors that can improve the performance of PPP projects. However, there is not much discussion in PPP literature on the difference between VFM factors and the PPP project success criteria. In project management literature, VFM factors are viewed as success enablers that can be controlled in the sense that they can be used as constructs to increase the success probability of a project (Müller and Turner, 2007).

The rationale for this study is that by establishing the relationship between PPP projects individual VFM factors and project success criteria, the stakeholders can take informed decisions before the award of the project, which will improve the success rates of the PPP project.

There are many studies that describe that VFM is quite important in carrying out successful PPP projects. Liu et al. (2014) have quoted the work of Yuan and others (2009) which describes that the value for money in a project can be described as the ability to achieve the mission objectives that are set up by the public client in a PPP project. It includes successfully achieving the requirements of the general public who will ultimately be using the project. Liu and others also cite the literature of Henjewele et al. (2011), as well as of Akintoye et al. (2003), which describe that VFM serves as a benchmark objective for PPP projects. They also reported that the requirements of the public client should serve as a tool for measuring the performance levels of PPPs. It is important to improve the efficiency and the economy of a PPP project in order to achieve the VFM targets. The value for money in a long term project can ensure that these partnerships can be continually developed in order to reach the desired monetary and social targets (Yuan et al., 2012, Cheung et al., 2005). According to a source, a business only succeeds if it performs according to a set of standards that are measured at the project level (Kagioglou et al., 2001).

On the other hand, project success criteria are a measure used to establish the success or failure of a project (Collins and Baccarini, 2004). Therefore, this study of the view that the VFM factors have an influence on the success criteria used for measuring the success of PPP projects. There are different methods for evaluating PPPs success. One of which is the ex-post evaluation method, which uses comparative analysis of the actual performance in a project to the expected objectives at the end, and also guides a future expansion (Liu et al., 2013; Irani et al., 2001; Irani et al., 2005). The use of success criteria that focusses on cost, time, quality, and scope are considered one of the most cited evaluation criteria for measuring project success or failure (Atkinson, 1999; Ika, 2009; Lazarević and Prlinčević, 2014; Shenhar and Dvir, 2007; Westerveld, 2003). Kušljić and Marenjak (2013) postulated that, "a PFI project can be described as successful if it delivers value for money in the form of cost effective, reliable and timely services at agreed prices and to agreed quality, as defined in the contract". Moreover, Liu and others (2013) discusses that there is still the lack of effective methods for measuring performance of PPP projects. This means that there is always a chance for having reduced service quality of the project. Thus, this study uses criteria for evaluating the success of PPP projects, where VFM factors are used as controlled independent factors to optimize the success of the evaluation criteria. Therefore. The question in this research study is to establish which of the VFM factors are good predictors of the PPP project success criteria. There is a need for strict criteria in order to describe the achievement of success in PPP projects. This criteria ensure that the actual practice can be measured against the criteria which are set at the start of the project (Williams, 2016). Thus, the aim of this study is to expand the PPP literature by establishing the association of the VFM factors and PPP projects success. The research uses a survey in order to establish important relationship between the different factors. This paper uses five sections to describe the complete concept. Section 2 presents a background and discussion regarding project value for money factors and PPP performance indicators, highlighting the established relationship between the two from current literature. Section 3 presents the methodological approach followed to derive the results. Section 4 presents an analysis of the results, and presents the discussion and the implication of the results. Section 5 presents the conclusions and the limitations of the research.

\section{Literature review}

PPP projects are very prevalent around the world. These projects are able to share risk and bring innovation and experience of the private sector. Such projects also use funds efficiently (Alfen, 2010; Almarri and Abu Hijleh, 2017). According to Broadbent and Laughlin (2004, p. 4), PPP projects are "long-term relationships involving the private sector in the provision of public services that in many cases had previously been entirely the responsibility of the public sector". The PPP projects require collaboration between government organisations and private companies. The whole purpose of this activity is to maximise the performance of both parties during the project development (Alfen, 2010; IAEA, 2012).

Currently, the PPP model is successfully employed in many countries. These countries include China, Germany, India and the UK, just to name a few of them. PPP projects are often capital intensive, and government resources are mostly quite limited. Private funding is able to cover the gap and ensure that public services can be quickly developed by the government without facing a finance crunch. When implemented in the right manner, these projects have the ability to provide a number of benefits. The important ones in this regard include technology transfer, better efficiency, improved quality and most importantly, risk sharing (Alfen et al., 2009; Almarri and Abu Hijleh, 2017). 
There are many features of PPP projects, such as long durations, many stakeholders, complex processes and high risks that capture the attention of researchers. Many studies have already reviewed PPP model in a systematic manner in order to find out how these projects work. Some researchers have also looked into these studies and found that these studies are undergoing great changes and expanding (Yuan et al., 2012; Yuan et al., 2009; Ke et al., 2009; Tang et al., 2010).

A source describes that VFM in PPP projects often requires the delivery of additional benefits and the best cost in the domain of public services (Akintoye et al. 2005). VFM works as a key factor, which the public sector uses to find if a certain project can perform better using the PPP model, rather than the traditional procurement method. Yuan et al. (2009) looked at the main object of a PPP, which is to get the best value for money in the following manner, "public client's overall strategic plan and mission objectives, private sector's long-term development and payoff strategy, the general public's requirements of quality public facilities and services". Henjewele et al. (2011) and Akintoye et al. (2005) presented that it is one of the benchmark objectives of any PPP to achieve improved VFM. Henjewele and others (2011) have also described, "Meeting client's requirements should be considered as a core dimension in performance measurement of PPPs". Ismail (2013) found that the most influence factors to enhance VFM "private sector technical innovation" and "competitive tender". Some of the determinants that cited in the literature include (Sobhiyah et al., 2009): reduced life cycle costs, creativity and innovation, faster implementation, longterm engagement, output specification, nature of the agreements, effective incentives mechanism, competition at several sections and better allocation of project. The studies clearly show that it is highly important to analyse the VFM in each PPP project. This tangible and intangible assessment can be made in a number of ways. One way to check performance is to use qualitative analysis. This analysis uses a number of guidelines and checks a PPP project against them in order to find if its structure matches that of the one described in the guidelines. Another approach to use is the quantitative analysis. This simply looks at the actual figures of a project and compares them to ideal values. It is common though to see that both approaches are used simultaneously to properly perform the appraisal of PPP projects. Such an approach looks at the economic benefits of the project, as well as the endured costs, which are adjusted according to the possible risk in the public project. These factors are usually measured against known values obtained from the traditional procurement models (P3, 2011; EPEC, 2012; WBI, 2012).

It is well understood in the PPP practices and literature that the overriding principle in determining if a project is to be procured under PPP is VFM. The main focus of PPP is to generate VFM through whole-of-life costing, managing risks and protecting the public interest (Boussabaine, 2014). The majority of the PPP literature point to the fact that PPPs are perceived to be successful if they deliver the anticipated benefits. However, the PPP method is also criticised for not delivering VFM as planned in the appraisal of the projects. While VFM studies are used to decide for opting for the PPP procurement method, there is no clear evidence on how the VFM factors potentially lead the success or otherwise of PPP projects. This type of ex-ante benefit analysis of VFM is not sufficient to ensure that a project will deliver the anticipated benefits. Thus, this research is endeavouring to establish if there is any relationship between the VFM factors and the PPP project performance in terms of project success criteria. As stated previously, the creation of value is one of the fundamentals of PPP procurement. It is presumed in the traditional procurement that the VFM should be associated with the lowest cost option, but rather it should be associated with the whole tangible and intangible benefits associated the project (Boussabaine, 2014). Although PPPs may be supported by positive analyses, they can always face unforeseen hurdles that can hinder their performance. These obstacles include financial, technological and coordination problems that may impact the normal performance of a PPP project. All of these obstacles decrease the VFM of a project and can change the complete dynamics of the project, as they are often long term prospects. The presence of these issues means that there is always a need to find solutions that can overcome these problems. Although VFM is predefined in PPP projects for the purpose ex-ante evaluation the VFM can evolve during the operation of the contract. Hence, the inclusion in conditions of the PPP agreement for benchmarking of the output services. One of the solutions that was postulated in the literature is to use project success criteria to capture the performance of projects at any time during the life cycle. It is understood that success factors are the instruments that facilitates the accomplishment of project objectives (Turner, 2007). It is also pointed that the CSFs depend on the type and life cycle of the project. The thrust behind using the CSFs is to improve the project management successes leading to the success of the project. Since the beginning of the PPP procurement method a plethora of researchers have utilised the concepts of CSFs factors to augment our understanding of the performance of PPP projects implementation and operation. The CSFs concept has been used at different types and life cycle of projects. However, very little has been written on the association between VFM drivers and project success criteria.

\subsection{Research Model}

The above findings from the literature demonstrated that VFM has an influence on the performance of PPP projects. This research presents the hypothesis that VFM factors are associated with the performance (in terms of success criteria) of PPP projects. This research aims to study the influence of multiple VFM factors and find their association with the performance of PPP projects. Therefore, this study hypothesizes that there is a strong association between the VFM factors and the performance of PPP projects in terms of time, cost, quality, service, economic benefits, and variation performance. Based on these assumptions and literature review, the authors formulated the following hypothesis to operationalize this search question.

\subsection{Hypothesis}

There is positive relationship between perceived PPP project success criteria and perceived VFM factors.

The hypotheses were tested using bi-variate correlation and multiple stepwise regression analysis. The results are presented and discussed in the following sections. The 
conceptual framework of this research is portrayed in Fig. 1 .

\subsection{Independent Variables}

The independent variables are VFM factors. These factors used and validated in previous studies. This research will consider the VFM factors that are described in the research of $\mathrm{Li}$ and others (2005). There are a large number of studies that clearly recognise the practices and factors that are presented in this research (Cheung et al., 2009; Chou and Pramudawardhani, 2015; Hwang et al., 2013; Robert et al., 2014; Ismail, 2013; Osei-Kyei et al., 2015). $\mathrm{Li}$ and others performed an extended literature review in order find the important value for money factors in the UK. Each of these factors was only selected if supported by a large number of research studies. Li et al. (2005) found the following factors that enhance the value for money in a project: competitive bidding, good dispute resolutions, early servicing, specific outputs, improved user facilities, and reduced negative environmental impact. Other recognised factors include low costs, low rates, efficiency of asset utilisation, incentives, long-term work, project management, technological edge, risk allocation, community services and improved capital management (Table 1).

\subsection{Dependent Variables}

The dependent variables are the measures used to assess the success of PPP projects. It is well established in the literature of project management that project success criteria are the metrics used to evaluate whether a project is being executed according to the predefined success criteria. Generally, project success criteria can vary based on the type of the project. There is to a certain extend consensus that project success is measured at least by the golden triangle, cost, time and quality. However, it is pointed that there is a lack of acceptable frameworks for assessing PPP projects success "There are still no accepted frameworks for assessing project success and there is no agreement on a standard, or even an operative framework for assessing project success" (Marenjak, 2017). Several other studies also stated that there is a need to develop metrics for the success of PPP projects (Audit Commission, 2003). This study uses six measures of success (time, cost, quality, service, economic benefits, and variation performance). These are used and validated in the previous studies (Atkinson, 1999; Ika, 2009; Lazarević and Prlinčević, 2014; Shenhar and Dvir, 2007; Westerveld, 2003). These are dependent variables which measure the project success. What this paper is trying to address is whether project success can be predicted from the VFM factors. If this can be the case, then VFM factors can be used as an optimisation tool to ensure the project success.

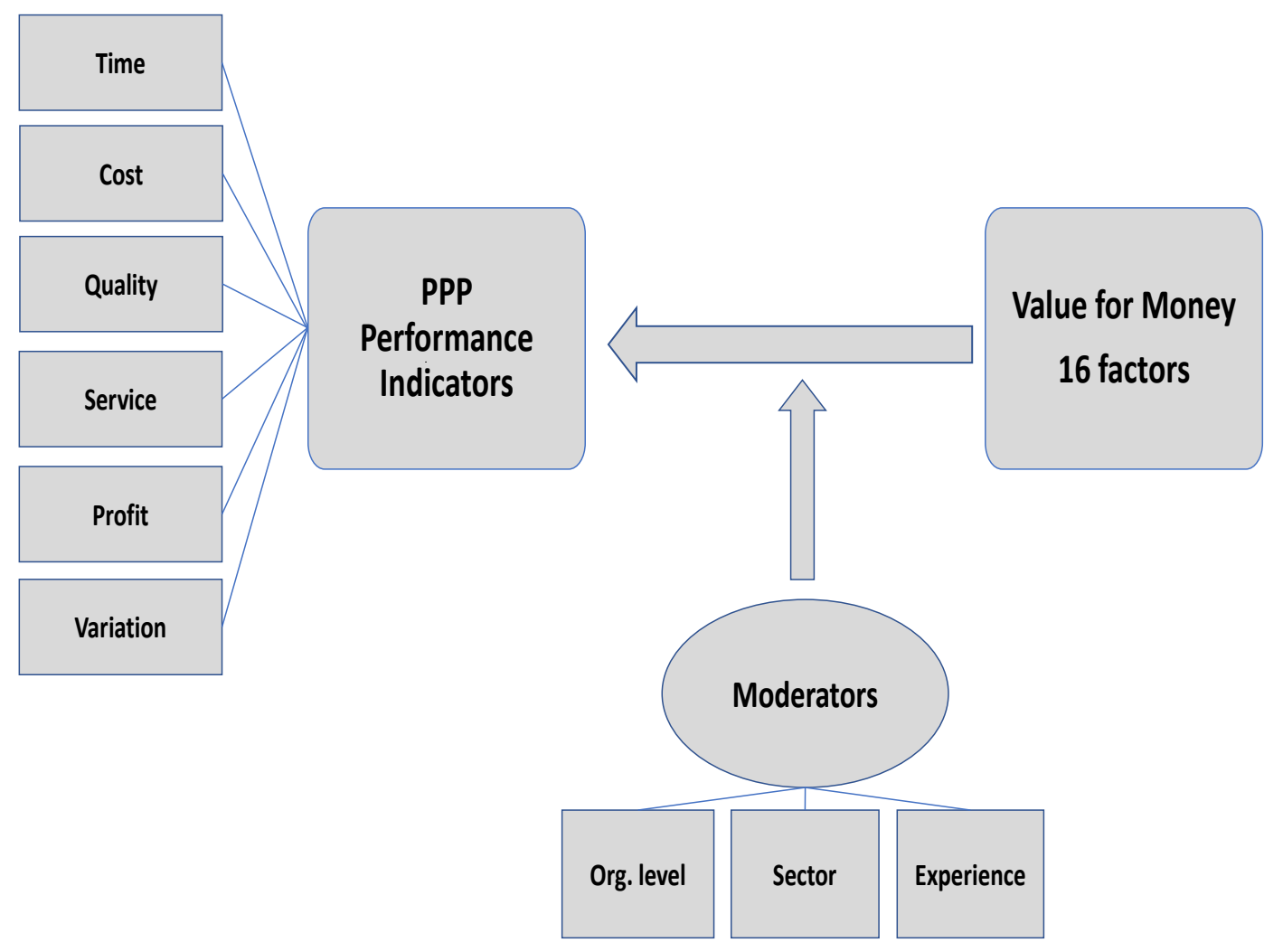

Fig. 1. Conceptual framework 


\section{Methodology}

The data was collected via an online questionnaire. The questionnaire consisted of VFM factors, PPP performance indicators and several demographic questions. The questionnaire used in this research consisted of three sections. The first section included the purpose of the study and ethical issues related to anonymity and confidentiality of information. The second section covered 4 demographic questions. The VFM section consisted of statements about the established 16 VFM factors (Table 1). The respondents evaluated the contribution of VFM to PPP performance using a 5-point scale. The last section included the 6 items to measure the performance of PPP projects.

This research was aimed at explaining the perception of experts on PPP projects performance at a point in time (Bryman and Bell, 2007). This approach is also deemed to have the advantage of generating acceptable responses from a wide range of experts. Furthermore, to explain a particular existing phenomenon, it is claimed that it is associated with objective and accurate data collection (Nwadinigwe, 2005).

Multiple linear regression technique was utilised to investigate the relationship between VFM drivers and project success in terms of cost, time, quality, economic benefits, variation and service output (Table 2). In our experiment, the project success criteria are considered as linear combination of the VFM explanatory variables. VFM explanatory variables were entered into the regression model stepwise as categorical variables (Table 3 ) and their association to success criteria is computed according to the following equation (Field, 2005):

$y_{i}=\beta 0+\beta 1 \times 1 i+\beta 2 \times 2 i+\beta 3 x 3 i+\ldots+\beta j x j i+\varepsilon i$

Where yi is the success criterion I (time, cost, quality, etc), $\beta=$ constant and the intercept at the $\mathrm{y}$ axis, $\beta \mathrm{j}=$ estimated regression coefficients; $x i \mathrm{j}=$ values of the independent or VFM drivers ; $\varepsilon i=$ residual term.

Table 1. VFM Factors

\begin{tabular}{|ll|}
\hline VM1 & Clear output specification \\
VM2 & Competitive bid process \\
VM3 & Early service delivery \\
VM4 & Efficient dispute resolutions \\
VM5 & Reduced negative environmental impact \\
VM6 & Appropriate capital structure \\
VM7 & Improved facilities to the users \\
VM8 & Optimised risk allocation \\
VM9 & Improved services to the community \\
VM10 & Incentives for private party \\
VM11 & Long-term engagement \\
VM12 & Low life-cycle cost \\
VM13 & Low tariffs \\
VM14 & Optimisation of assets efficiency \\
VM15 & Private sector's project management skills \\
VM16 & Technical innovation \\
\hline
\end{tabular}

The investigation was carried out among 92 PPP experts in the UK and the UAE. The study used purposive sampling. PPP practice groups were contacted for participation in the online questionnaire. $6.5 \%$ of the participants had less than 6 years of experience, $26 \%$ had 6-10 years of experience, $42 \%$ had $11-20$ years of experience, and $23 \%$ of the participants had more than 20 years of experience. The participants were from the public and the private sectors, in addition to the academics. The academics constituted $12 \%$ of the respondents, the public sector practitioners $25 \%$, and the private sector practitioners the remaining $63 \%$. The organisational level of the participants was $37 \%$ top management, $50 \%$ middle management, and $22 \%$ general staff.

Then Pearson's Correlation analysis was employed to find the correlation between the VFM and PPP performance indicators. Finally, stepwise multiple regression analysis was conducted to test the hypotheses as shown in the research theoretical framework. Further regressions were conducted to assess the influence of mediating variables on the dependent variable. The results showed that none of the mediating variables had a significant effect on the performance indicators.

\section{Results and discussion}

The correlation between the VFM and performance indicators was low. The presence of high (above 0.9) correlation between dependent and independent variables could signify collinearity. Because the correlation results are below 0.9, this suggests that there was no multicollinearity between the variables used in this research instrument.

Furthermore, multicollinearity was assessed by the variance inflation factor (VIF). It is reported that if the value of VIF is below 10, it can be considered as a proof of no multicollinearity between the variables of the experiment. In this research, all the generated regression analysis shows the VIF values below 10 . Thus, it can be confirmed that there was no multicollinearity between research constructs.

The first hypothesis was designed to examine whether VFM can affect the performance of PPP projects, in terms time to completion. The results demonstrated that VM7 contributed positively to time performance $(\beta=0.261$, $\mathrm{p}=.004)$. The stepwise regression analysis also revealed that these factors contributed $7.6 \%$ of the variance to time performance. In PPP projects, the quality of services must be maintained throughout the life cycle of the concession.

This research confirms that VM7 "Improved facilities to the users", is a latent variable for assessing PPP projects performance in relation to time, quality and project scope variation. Our findings are supported by Enoma (2015) that the emphasis should be, "placed on the attainment of value for money, Customer satisfaction and the delivery of a better building; that is economic to run, easy for the occupiers to maintain, control and manage, better able to respond to the needs of the occupant". It is not surprising to see that service improvement to the public users, can add value to the PPP projects. In fact, the main driver behind the paradigm of PPP procurement is achieving value for money by providing all the necessary service provisions at an optimal cost and to the output specified standards. This view is further articulated by Moss and Alexander (2007) in pointing out that "increase in employee/user satisfaction" should be considered as a value creation driver.

The second hypothesis was formulated to assess the contribution of VFM to the cost performance of PPP 
projects. The study revealed that only VM3 "Early service delivery" $(\beta=.200 p=.014)$ contributed to the success of the cost of PPP projects. The stepwise regression analysis also revealed that this factor contributed only $5.5 \%$ of the variance to time performance. The implication is that the cost performance cannot be determined by all the VFM factors associated with this study. However, in relevant literature, VM3 is advocated by several studies as one of the key value for money objectives. Early delivery of PPP projects can be associated with better utilisation of the assets, leading to providing financial value to the service provider (Caballer-Tarazona and Vivas-Consuelo, 2016). This also is associated with the efficient use of PPP projects in delivering necessary public services, for creating wide social benefits.

The third hypothesis was framed to assess the contribution of VFM to the quality performance of PPP projects. The results are similar to the cost performance assessment. The study revealed that only VM7 $(\beta=0.084$, $\mathrm{p}=.008$ ) contributed to the success of the cost of PPP projects. The stepwise regression analysis also revealed that this factor contributed only $6.6 \%$ of the variance to time performance. The implication is that the quality performance of PPP schemes cannot be determined by all the VFM factors associated with this research. The performance of PPP schemes is specified in terms of the quality of the required outputs. PPP promotes quality/technical performance and quality of service delivery. If the anticipated quality value from the performance is not delivered as stipulated under the contract payment, deduction can be triggered to compensate for the lost value.

The fourth hypothesis was framed to assess the contribution of VFM to the service performance of PPP projects. The study demonstrated that VM1 "Clear output specification" $(\beta=0.228, p=.003)$ contributed positively to the success of the service performance of PPP projects. The stepwise regression analysis also revealed that these factors contributed only $8.4 \%$ of the variance to service performance. This research agrees that clear output specifications are essential to robust PPP concession and the performance delivery of the services (Sanders and Lipson, 2001). Also, Javed et al. (2013) support our findings in the sense that "a good set of output specifications is conducive to the achievement of value for money, innovation, risk transfer, whole life asset performance through a clear abatement regime and an effective linkage of performance criteria to the payment mechanism". It is universally accepted that the operational performance of PPP projects has a remarkable impact on achieving the long value for money success. Thus, the identification of these two latent and key variables might help in developing a benchmark about the most important service performance factor for VFM.

The fifth hypothesis was designed to examine whether VFM can predict performance of PPP projects in terms of economic benefits performance. The results also demonstrated that VM12 "Low life-cycle cost" contributed positively to time performance $(\beta=0.228$, $\mathrm{p}=.003)$. The stepwise regression analysis also revealed that these factors contributed $8.4 \%$ of the variance to economic benefits performance. It is well acknowledged in literature that better value does not mean the lowest life cycle cost alone. Under the PPP procurement systems, the private sector is required to optimise the life cycle cost. The private sector is encouraged to undertake quality enhancement in the provision of the services, to increase the user's welfare at lower life-cycle costs than a conventionally procured project.

The sixth hypothesis was formulated to assess whether VFM can predict performance variation of PPP projects, in terms of specification and scope change. The results demonstrated that 3 VFM factors contributed to the performance. The results indicated that VM7 and VM16 "Technical innovation" contribute positively to time performance $(\beta=0.270, p=.011, \beta=0.248, p=.036)$. It is also supported in the literature that technical innovation has an influence on the service provision quality and life cycle cost of PPP assets. The performance of these PPP dimensions is enhanced, through the introduction of technical innovations by the private sector. VM14 contributes negatively to variance performance $(\beta=-0.503$, $\mathrm{p}=.00)$. The stepwise regression analysis also revealed that these factors contributed $17.8 \%$ of the variance to economic benefits performance. This result may imply that VM14 "Optimisation of assets efficiency" if not synchronised with the service output specification leads to the scope of variation. This confirms the view that life cycle optimisation of the PPP assets represents the best value creation (Boussabaine, 2013), for creating efficient and sustainable PPP concessions.

Table 2. Simple regression results

\begin{tabular}{lccccc}
\hline \multicolumn{1}{c}{ Performance Indicators } & $\mathrm{R}^{2}$ & Adj. R2 & SSE & F & Sig \\
\hline Model -time performance & .086 & .076 & .673 & 8.522 & .004 \\
Model -cost performance & .066 & .055 & .705 & 6.344 & .014 \\
Model -quality & .076 & .066 & .633 & 7.417 & .008 \\
Model -service & .094 & .084 & .589 & 9.315 & .003 \\
Model -economic benefits & .252 & .235 & .775 & 5.341 & .023 \\
Model-variation & .214 & .178 & .692 & 4.561 & .036 \\
\hline
\end{tabular}


Table 3. Stepwise regression results

\begin{tabular}{lcccccccccccc}
\hline \multirow{2}{*}{ Perf. Predic. } & \multicolumn{2}{c}{ Time } & \multicolumn{2}{c}{ Cost } & \multicolumn{2}{c}{ Quality } & \multicolumn{2}{c}{ Service } & \multicolumn{2}{c}{ Econ-benefits } & \multicolumn{2}{c}{ Variation } \\
\cline { 2 - 12 } & $\beta$ & Sig & $\beta$ & Sig & $\beta$ & Sig & $\beta$ & Sig & $\beta$ & Sig & $\beta$ & Sig \\
\hline Model Constant & 3.26 & .000 & 3.69 & .000 & .333 & .000 & 3.50 & .000 & 1.231 & .008 & 2.761 & .000 \\
VM7 & .261 & .004 & & & .084 & .008 & & & .261 & .023 & .270 & .011 \\
VM3 & & & .200 & .014 & & & & & & & & \\
VM1 & & & & & & & .228 & .003 & & & & \\
VM12 & & & & & & & & & .365 & .001 & .257 & .016 \\
VM14 & & & & & & & & & & & -.503 & .000 \\
VM16 & & & & & & & & & & & .248 & .036 \\
\hline
\end{tabular}

\section{Conclusions}

The endeavour to achieve value for money in PPP projects has increased the number of efforts undertaken within the academic and professional community. Several studies have attempted to investigate the factors and strategies, which contribute in creating VFM. This research established the difference between the VFM factors that contribute to the success of PPP projects, and the PPP projects success evaluation criteria, and how there is an association between the two. There are several factors that were reported in the relevant literature, to assist in the success of PPP projects. But there is a limited empirical research, which examines the relationship between the PPP project performance (specifically the ex-post performance) and the VFM creation factors. Thus, this research expands the existing literature on these important aspects of PPP procurement. It was found that there was a significant relationship between Improved facilities to the users and time, quality, economic benefits and scope variation performance of PPP projects. Thus, this confirms the view that end user satisfaction with the asset and services that respond to their needs, and are within the economic constraints, is essential for creating value and success of the project. Clear output specification and Early service delivery factors contribute only to the performance in terms of service and cost. The results of the analysis showed that Optimisation of assets efficiency factor contributed negatively to the scope of variation of projects. This finding is consistent with the existing literature. At least in this research, the regression analysis showed that sector, experience and job position have no mediating role between PPP projects' performance and VFM factors, which could be further emphasized in future studies. The findings of this study expand the current PPP literature, and pave the way for further empirical work to investigate the relationship between the VFM factors and the success of PPP projects. The implication of this study to practice is summarized, among others, in the benefits to the decision makers in local governments and private investors in making informed decisions about the investment, and the emphasis on certain VFM factors that contribute more to the PPP project success. This study has some limitations, among them is the sampling criteria selected for this study. The pool of PPP practitioners in the UK proved to be difficult to penetrate, and referrals were the only means of reaching qualified practitioners. Furthermore, the UAE sample was small due to the scarce PPP population. Hence the use of purposive sampling. Another limitation was that the findings of this study apply mostly to the contexts of the UAE and the UK.

\section{References}

Akintoye, A. and Chinyio, E. (2005). Private Finance Initiative in the healthcare sector: trends and risk assessment. Engineering, Construction and Architectural Management, 12(6), 601-616.

Akintoye, A., Hardcastle, C., Beck, M., Chinyio, E., and Asenova, D. (2003). Achieving best value in private finance initiative project procurement. Construction Management and Economics, 21(5), 461-470.

Alfen, H. (2010). Public Private Partnership (PPP) as part of Infrastructure Management solutions - a structural approach of delimiting PPP from other Private Sector participation Models. 18th CIB World Building Congress, May 2010 Salford, United Kingdom.

Alfen, H., Kalidindi, S., Ogunlana, S., Wang, S., Abednego, M., Frank-Jungbecker, A., and Zhao, G. (2009). Public-Private Partnership in infrastructure development: Case studies from Asia and Europe.

Almarri, K. and Abu Hijleh, B. (2017). Critical Success Factors for Public Private Partnerships in the UAE Construction Industry - A Comparative Analysis between the UAE and the UK. Journal of Engineering, Project, and Production Management, 7(1), 21.

Almarri, K. and Blackwell, P. (2014). Improving risk sharing and investment appraisal for PPP procurement success in large green projects. Procedia-Social and Behavioral Sciences, 119, 847-856.

Ameyaw, E. and Chan, A (2015) Risk allocation in public-private partnership water supply projects in Ghana, Journal Construction Management and Economics, Volume 33, 2015 - Issue 3.

Atkinson, R. (1999). Project management: Cost, time and quality, two best guesses and a phenomenon, it's time to accept other criteria. International Journal of Project Management, 17, 337-342.

Audit Commission (2003). PFI in Schools, London, United Kingdom, 2003.

Boussabaine, A. H. (2013). Public private partnership projects: Risk pricing strategies, in print Pub by. Hoboken, NJ: Wiley-Blackwell.

Broadbent, J. and Laughlin, R. (2003). Public private partnerships: an introduction. Accounting, Auditing and Accountability Journal, 16(3), 332-341. 
Broadbent, J. and Laughlin, R. (2004). PPPs: Nature, development and unanswered questions. Australian Accounting Review, 14(33), 4-10.

Bryman, A. and Bell, E. (2007) Business Research Methods. Oxford University Press. Oxford.

Caballer-Tarazona, M. and Vivas-Consuelo, D. (2016). A cost and performance comparison of Public Private Partnership and public hospitals in Spain. Health economics review, 6(1), 17.

Cheung, E. (2009). Developing a best practice framework for implementing public private partnerships (PPP) in Hong Kong. Ph.D. Thesis. Queensland University of Technology.

Cheung, E., Chan, A. P., Lam, P. T., Chan, D. W., and Ke, Y. (2012). A comparative study of critical success factors for public private partnerships (PPP) between Mainland China and the Hong Kong Special Administrative Region. Facilities, 30(13/14), 647-666.

Chou, J. S., Tserng, H. P., Lin, C., and Yeh, C. P. (2012). Critical factors and risk allocation for PPP policy: Comparison between HSR and general infrastructure projects. Transport Policy, 22, 36-48.

Chou, J. and Pramudawardhani, D. (2015). Cross-country comparisons of key drivers, critical success factors and risk allocation for public-private partnership projects. International Journal of Project Management., 33(5), 1136-1150.

Collins, A. and Baccarini, D. (2004) Project Success - A Survey. Journal of Construction Research, 5(2), 211231.

Enoma, A. (2005). The role of facilities management at the design stage. In 21st Annual ARCOM Conference (Vol. 1, pp. 421-430).

EPEC- The European PPP Expertise Centre. (2012). The Guide to Guidance: How to Prepare, Procure and Deliver PPP Projects.

EU- European Commission. (2003). Guidelines for successful public - private partnerships. DirectorateGeneral Regional Policy, Directorate General for Research. Brussels.

Field, A. (2005) Discovering statistics using SPSS. London: SAGE Publications.

Haponava, T. and Al-Jibouri, S. (2012) Proposed system for measuring project performance using process-based key performance indicators, Journal of Management in Engineering, 28(2), 140-49.

Henjewele, C., Sun, M., and Fewings, P. (2011). Critical parameters influencing value for money variations in PFI projects in the healthcare and transport sectors. Construction Management and Economics, 29(8), 825839.

Ika, L. A. (2009). Project success as a topic in project management journals. Project Management Journal, 40(4), 6-19.

Irani, Z., Sharif, A., and Love, P. E. D. (2005) Linking knowledge transformation to information systems evaluation, European Journal of Information Systems, 14(3), 213-18.

Irani, Z., Sharif, A., and Love, P. E. D. (2001) Transforming failure into success through organizational learning: an analysis of a manufacturing information system, European Journal of Information System, 10(1), 55-66.
Ismail, S. (2013). Drivers of value for money public private partnership projects in Malaysia. Asian Review of Accounting, 21(3), 241-256.

Javed, A. A., Lam, P. T., and Zou, P. X. (2013). Outputbased specifications for PPP projects: lessons for facilities management from Australia. Journal of Facilities Management, 11(1), 5-30.

Kagioglou, M., Cooper, R., and Aouad, G. (2001). Performance management in construction: a conceptual framework. Constr. Manage. Econ., 19(1), 85-95.

Ke, Y., Wang, S., Chan, A. P., and Cheung, E. (2009). Research trend of public-private partnership in construction journals. Journal of Construction Engineering and Management, 135(10), 1076-1086.

Kusljic, D. and Marenjak, S. (2013). Critical PPP/PFI project success criteria for public sector clients/Kriticni kriteriji uspjeha JPP/PFI projekata za narucitelje. Tehnicki vjesnik-Technical Gazette, 20(6), 947-955.

Kušljić, D. and Marenjak, S. (2013). Critical PPP/PFI project success criteria for public sector clients. Tehnički vjesnik/Technical Gazette, 20(6), 947954.

Kwak, Y. H., Chih, Y. Y., and Ibbs, C. W. (2009) Towards a comprehensive understanding of public private partnerships for infrastructure development, California Management Review, 51(2), 52-78.

Lazarević, D. and Prlinčević, B. (2014). Project Management: Cost, Time and Quality. Center for Quality.

Li, B., Akintoye, A., Edwards, P. J., and Hardcastle, C. (2005). Critical success factors for PPP/PFI projects in the UK construction industry. Construction Management and Economics, 23(5), 459-471.

Liu, J., Love, P. E., Davis, P. R., Smith, J., and Regan, M. (2013). Performance measurement framework in PPP projects. In A. Akintoye, C. Liyanage, and J. Goulding (Eds.), P3BooK Proceedings of International Conference on PPP Body of Knowledge in Preston, UK, University of Central Lancashire, Lancashire (pp. 5564).

Liu, J., Love, P., Davis, P., Smith, J., and Regan, M. (2014). Conceptual framework for the performance measurement of public-private partnerships. Journal of Infrastructure Systems, 21(1).

Meyer, K. S. (2012). Testing Tradition: Assessing the Added Value of Public-Private Partnerships. The National Council for Public-Private Partnerships, Arlington, VA.

Moss, Q. and Alexander, K. (2007). Performance measurement action research. Journal of Facilities Management, 5(4), 290-300.

Müller, R. and Turner, R. (2007). The Influence of Project Managers on Project Success Criteria and Project Success by Type of Project, European Management Journal, Vol.25, No.4, pp. 298-309.

Nwandinigwe, I. P. (2005). Fundamentals of Research Methods and Statistics. Lagos: Sibon Books Limited

Osei-Kyei, R. and Chan, A. (2015). Review of studies on the Critical Success Factors for Public-Private Partnership (PPP) projects from 1990 to 2013. International Journal of Project Management, 33(6), 1335-1346. 
P3-The Canadian council for PPP (2011). Public-Private Partnerships: A guide for municipalities.

Regan, M., Smith, J., and Love, P. E. D. (2011) Impact of the capital market collapse on public-private partnership infrastructure projects, Journal of Construction Engineering and Management, 137(6), 616.

Sanders, S. and Lipson, M. (2001). Output Specifications for PFI Projects: A 4Ps Guide for Schools. Public Private Partnerships Programme (4Ps), London.

Shenhar, A. J. and Dvir, D. (2007). Reinventing project management: the diamond approach to successful growth and innovation. Harvard Business Review Press.

Sobhiyah, M. H., Bemanian, M. R., and Kashtiban, Y. K. (2009). Increasing VFM in PPP power station projectsCase study: Rudeshur gas turbine power station. International Journal of Project Management, 27(5), 512-521.

Tang, L., Shen, Q., and Cheng, E. W. (2010). A review of studies on public-private partnership projects in the construction industry. International Journal of Project Management, 28(7), 683-694.

Westerveld, E. (2003). The project excellence model: Linking success criteria and critical success factors. International Journal of Project Management, 21, 411418.

Williams, T. (2016). Identifying Success Factors in Construction Projects: A Case Study. Project Management Journal, 47(1), 97-112.

Yuan, J., Wang, C., Skibniewski, M. J., and Li, Q. (2012). Developing key performance indicators for publicprivate partnership projects: Questionnaire survey and analysis. Journal of Management in Engineering, 28(3), 252-264.

Yuan, J., Zeng, A. Y., Skibniewski, M. J., and Li, Q. (2009). Selection of performance objectives and key performance indicators in public-private partnership projects to achieve value for money. Construction Management and Economics, 27(3), 253-270.

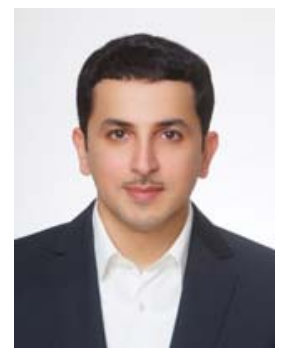

Dr Khalid is an assistant professor of project management at the Engineering and IT department of the British university in Dubai. Dr Khalid is proclaimed for setting high standard of accomplishment by holding the first $\mathrm{PhD}$ award in Project Management in the region. Dr Khalid has an undergraduate degree in Civil Engineering from the University of Arizona and master's degree in Engineering Management from the Catholic University of America. Following which he commenced his engineering career in 1996 in the Dubai Municipality and has been in the government services in the Sewerage \& Irrigation Department and the Roads Department as Head in the Roads Construction Section.

Dr Khalid holds the credential of having produced, through a doctoral program, the first framework for developing projects through public private partnerships (PPP) in the UAE. This framework is the first to lay the foundations for a standardized PPP practice in the UAE for practitioners. It highlights the most important factors for the success of PPP projects, such as value for money, risk sharing and allocation, renegotiations, and the roles of the public and private parties.

Dr Khalid is also credited for developing a framework for establishing a nuclear research reactor project in the UAE through the utilization of public private partnerships, which was one of the first frameworks for PPPs in research reactor projects in the world and followed strict safeguards and required full awareness of nuclear safety, security \& control of nuclear materials handling.

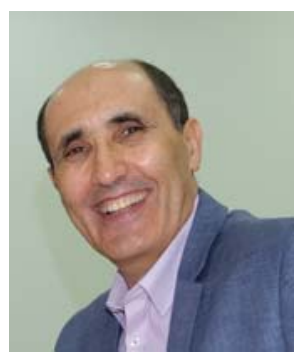

Boussabaine has more than 25 years of experience in risk modelling and management. He holds PhD and MSc from Manchester University in UK. His consistent research interest has been to pull together and integrates various modern scientific theories and the state of the art modelling techniques in order to gain a better understanding of the complexity of risk. Recently his research portfolio has been expanded to encompass the impact of emerging risks on a variety of complex human decisions that affect natural systems, social systems and human-made networks. He has published four books and over 100 research articles. He has supervised over 20 decorate research project. He acts as peer reviewer for many leading international journals. He assesses research proposals and final reports for UK and EU research councils. He has delivered training courses in UK, Europe, Asia and MENA regions. He is an honorary visitor to Liverpool and Manchester Universities in UK. 